\title{
Comparison of peri-implant bone loss between conventional drilling with irrigation versus low-speed drilling without irrigation
}

\author{
Hilario Pellicer-Chover ${ }^{1}$, David Peñarrocha-Oltra ${ }^{2}$, Amparo Aloy-Prosper ${ }^{3}$, José-Carlos Sanchis-Gonzalez ${ }^{4}$, \\ María Peñarrocha-Diago ${ }^{5}$, Miguel Peñarrocha-Diago ${ }^{6}$
}

\begin{abstract}
${ }^{1}$ DDS. Collaborating Professor of the Master in Oral Surgery and Implant Dentistry. Oral Surgery Unit, Department of Stomatology, Faculty of Medicine and Dentistry, University of Valencia, Spain

${ }^{2} \mathrm{PhD}$, DDS. Assistant Professor of Oral Surgery Unit, Department of Stomatology, Faculty of Medicine and Dentistry, University of Valencia, Spain

${ }^{3} \mathrm{PhD}$, DDS. Associate Professor of Oral Surgery, Stomatology Department, Faculty of Medicine and Dentistry, University of Valencia, Spain

${ }^{4}$ DDS. Master in Oral Surgery and Implant Dentistry, Oral Surgery Unit, Department of Stomatology, Faculty of Medicine and Dentistry, University of Valencia, Spain

${ }^{5} \mathrm{MD}$, PhD, DDS. Full Professor of Oral surgery Unit, Department of Stomatology, Faculty of Medicine and Dentistry, University of Valencia, Spain

${ }^{6} \mathrm{MD}$, PhD. Chairman of Oral Surgery and Director of the Master in Oral Surgery and Implant Dentistry, Oral surgery Unit, Department of Stomatology, Faculty of Medicine and Dentistry, University of Valencia, Spain
\end{abstract}

Correspondence:

Clínica Odontológica, Unidad de Cirugía Bucal

Gascó Oliag 1, 46021 - Valencia, Spain

miguel.penarrocha@uv.es

Received: $25 / 10 / 2016$

Accepted: $14 / 05 / 2017$

\begin{abstract}
Pellicer-Chover H, Peñarrocha-Oltra D, Aloy-Prosper A, SanchisGonzalez JC, Peñarrocha-Diago MA, Peñarrocha-Diago M. Comparison of peri-implant bone loss between conventional drilling with irrigation versus low-speed drilling without irrigation. Med Oral Patol Oral Cir Bucal. 2017 Nov 1;22 (6):e730-6.

http://www.medicinaoral.com/medoralfree01/v22i6/medoralv22i6p730.pdf
\end{abstract}

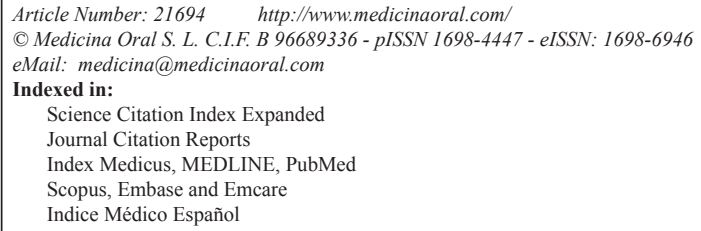

\begin{abstract}
Background: To compare the technique of high speed drilling with irrigation and low speed drilling without irrigation in order to evaluate the success rate and peri-implant bone loss at 12 months of follow-up.

Material and Methods: A randomized, controlled, parallel-group clinical trial was carried out in patients requiring dental implants to rehabilitate their unitary edentulism. Patients were recruited from the Oral Surgery Unit of the University of Valencia (Spain) between September 2014 and August 2015. Patients who met the inclusion criteria were randomized to two groups: group A (high-speed drilling with irrigation) and group B (low-speed drilling without irrigation). The success rate and peri-implant bone loss were recorded at 12 months of follow-up.

Results: Twenty-five patients ( 9 men and 16 women) with 30 implants were enrolled in the study: 15 implants in group A and 15 implants in group B. The mean bone loss of the implants in group A and group B was $0.83 \pm 0.73 \mathrm{~mm}$ and $0.62 \pm 0.70 \mathrm{~mm}$, respectively ( $p>0.05$ ). In the maxilla, the bone loss was $1.04 \pm 0.63 \mathrm{~mm}$ in group $\mathrm{A}$ and $0.71 \pm$ $0.36 \mathrm{~mm}$ in group B ( $p>0.05)$, while bone loss in the mandible was $0.59 \pm 0.80 \mathrm{~mm}$ in group A and $0.69 \pm 0.77 \mathrm{~mm}$ in group B $(p>0.05)$. The implant success rate at 12 months was $93.3 \%$ in group A and $100 \%$ in group B.

Conclusions: Within the limitations of the study, the low-speed drilling technique presented peri-implant bone loss outcomes similar to those of the conventional drilling technique at 12 months of follow-up.
\end{abstract}

Key words: Low-speed without irrigation, drilling technique. 


\section{Introduction}

The conventional drilling technique at $1500 \mathrm{rpm}$ described by Bränemark is currently the gold standard in most of implant systems (1). Recently, a new concept of low-speed drilling (50 rpm) without irrigation has been suggested as an alternative to the conventional procedure.

Many studies (2-6) have shown temperature alterations in bone during osteotomy, and significant temperatures increases can result in heat-induced bone injury (7). Calvo-Guirado et al. (8) evaluated a new hybrid drilling protocol involving the analysis of thermal changes in vitro and their effects on crestal bone loss and bone-to-implant contact in vivo. They found that the new hybrid protocol for preparation of the implant bed without irrigation increases the temperature in a way similar to the conventional incremental protocol. Crestal bone loss and boneto-implant contact with the new drilling protocol were comparable to those of the conventional drilling protocol, and did not affect the osseointegration process in vivo.

Different bone models based on cadaveric bone blocks from cow or pig have been used to record temperatures during drilling (9-12). Three studies used synthetic blocks (13-15) and one used a resin model (16). To our knowledge, no clinical study has compared the peri-implant bone reaction in conventional drilling with irrigation versus low-speed drilling without irrigation. For these reasons, the effects of the drilling technique upon bone healing around dental implants remain unclear. The objective of this study was to compare the techniques of high speed drilling with irrigation versus low speed drilling without irrigation, in order to evaluate the success rate and periimplant bone loss at 12 months of follow-up.

\section{Material and Methods}

-Patient screening and recruitment

A randomized, controlled, parallel-group clinical trial was carried out involving patients requiring dental implants to rehabilitate their unitary edentulism. Patients were recruited from the Oral Surgery Unit of the University of Valencia (Spain) between September 2014 and August 2015. Table 1 shows the inclusion and exclusion criteria. The investigation was performed following the principles outlined in the Declaration of Helsinki, and the patients were required to sign a consent form after being fully informed about the study. The study protocol was approved by the Institutional Review Board of the University of Valencia (H1365580155510).

-Preoperative procedure

Upper and lower alginate impressions were taken from each patient for planning and fabricating measurement stents and surgical guides. Cone-beam computed tomography (CBCT) (Picasso Master 3D®, Ewoo Technology, South Korea) was performed in all patients after placing a radiological stent marked with radiopaque material at the center of the missing tooth, in order to determine the exact implant site. Imaging was performed with a resolution of 0.1 voxels vision vision, a field-of-view (FOV) of $20 \mathrm{~cm} \times 19 \mathrm{~cm}$, and a slice interval of $1 \mathrm{~mm}$.

Bone density was calculated using the cross-section determined by the radiopaque marker, designating a study area of the same dimensions as the implant according to the indications of Turkyilmaz et al. (17), and obtaining measurements of the bone density in that area with Ezimplant ${ }^{\circledR}$ software (Vatech, Yongin-Si, South Korea), expressed in pixels (PV) as described by Song et al. (18). All patients received professional prophylaxis two weeks before surgery, and were given instructions for improving and maintaining oral hygiene at home. The patients received a removable, provisional prosthesis during the healing phase.

After six months of tooth socket healing, each patient was randomized to one of two treatment regimens: group A (conventional high-speed drilling technique with irrigation) or group B (low-speed drilling technique without irrigation). Random assignment was performed by a professional statistician using pre-defined randomization tables. A balanced random permuted-block approach was used to prepare the randomization tables, in order to avoid unequal balance between the two treatment groups. Participants were informed about treatments, but blinded to assignment.

-Surgical procedure

All surgeries were performed under local anesthesia (4\% articaine with 1:100,000 adrenalin [Inibsa $\AA$, Lliça de Vall, Barcelona, Spain]). Ticare ${ }^{\circledR}$ Inhex ${ }^{\circledR}$ implants

Table 1: Patient inclusion and exclusion criteria.

\begin{tabular}{|c|c|}
\hline Inclusion criteria & Exclusion criteria \\
\hline Healthy adults & Any patient requiring bone grafting procedures \\
\hline Full mouth plaque score and bleeding score $<25 \%$ & $\begin{array}{c}\text { Medical conditions contracting implant surgery, smokers, severe } \\
\text { bruxism or poor oral hygiene }\end{array}$ \\
\hline $\begin{array}{c}\text { Sufficiente bone hight and with to place one implant with } \\
\text { a min. length of 10mm and min diameter of 3,75mm. }\end{array}$ & $\begin{array}{c}\text { Pregnant or nursen patients, bisfosfonate therapy, patients receiveng } \\
\text { neck chemo- or radiotherapy }\end{array}$ \\
\hline Stable occlusion and healthy periodontium & $\begin{array}{c}\text { Non-collaborative patients, incomplete data gathering or failure to } \\
\text { attend control appointments }\end{array}$ \\
\hline
\end{tabular}


(Mozo-Grau, S.L. Valladolid, Spain) were used in the present study, presenting a neck design with microthreads, a rough surface up to the implant platform, a conical connection and platform switching. All patients were treated following a two-step procedure. Calibrated drills with stoppers were used to prepare the sites to the implant length at $800 \mathrm{rpm}$ with saline irrigation (group A) or at 50 rpm without irrigation (group B). The drill sequence used was: initial lance drill, followed by $2.0 \mathrm{~mm}$, $3.0 \mathrm{~mm}, 3.3 \mathrm{~mm}$ and $3.8 \mathrm{~mm}$ conical drills. After implant placement and suturing, each patient received $500 \mathrm{mg}$ of amoxicillin (19) (Clamoxyl ${ }^{\circledR}$, GlaxoSmithKline, Madrid, Spain) three times daily for 7 days, $600 \mathrm{mg}$ of ibuprofen (Bexistar ${ }^{\circledR}$, Laboratorio Bacino, Barcelona, Spain) to be taken as needed, and a $0.12 \%$ chlorhexidine mouthwash (GUM ${ }^{\circledR}$, John O. Butler/Sunstar, Chicago, IL, USA) for use twice daily during two weeks. Gentle brushing was also recommended. Sutures were removed 8-10 days after surgery. Prosthetic loading was carried out 8 weeks following implant placement.

All the restorations were metal-ceramic and screwed directly to the implant, and were designed and fabricated by the same dental technician. All the structures were designed by the same dental technician and CAD-CAM drilled out of chromium-cobalt at the facilities of the implant manufacturer (Bio-CAM, Mozo-Grau, S.L., Valladolid, Spain). The same dental technician then provided the feldspatic ceramic veneering [IPS d.SIGN, Ivoclar Vivadent, Schaan, Liechtenstein]. All screws were tightened with a torque of $30 \mathrm{Ncm}$ according to the specifications of the manufacturer. The access hole of the screwretained crowns was closed with a teflon pellet and a hybrid resin composite [Tetric-Ceram, Ivoclar Vivadent, Schaan, Liechtenstein].

-Measurements

A previously established standard protocol was used to compile the following data for all patients: sex, age (at implant placement), implant length, implant diameter, and tooth brushing frequency.

The definition of implant success was based on the clinical and radiographic criteria described by Buser et al. (20): 1) absence of clinically detectable implant mobility; 2) absence of pain or any subjective sensation; 3) absence of recurrent peri-implant infection; and 4) absence of persistent radiotransparency around the implant after 12 months of loading.

Radiological evaluation was carried out at the time of implant placement (T1) and 12 months after loading (T2) using an XMIND intraoral system (GroupeSatelec-Pierre Rolland, Bordeaux, France) and an RVG intraoral digital receptor (Dürr Dental, Bietigheim-Bissingen, Germany). To reproduce the patient alignments, a rigid cross-arch bar was used with bite-registration material, and a Rinn XCP (Dentsply, Des Plaines, IL, USA) rod and ring were firmly attached to the bar and placed in contact with the
X-ray cone. The receptor was held by a slot in the bar. Two trained clinicians worked together to interpret the radiographs. Implant marginal bone level was measured to the closest $0.1 \mathrm{~mm}$ using DBSWIN software (Dürr Dental, Bietigheim-Bissingen, Germany). For measurement purposes, two visible and easily localized reference points were selected at the implant platform. A straight line was traced joining the two reference points and was taken to represent zero height. For the determination of bone level, a perpendicular line was traced mesial and distal to the implant from zero height to contact with the bone (Fig. 1). The difference between the values recorded at $\mathrm{T} 1$ and $\mathrm{T} 2$ was used to calculate bone loss mesial and distal to the implant. The average between mesial and distal was selected as the bone loss for the fixation in question.

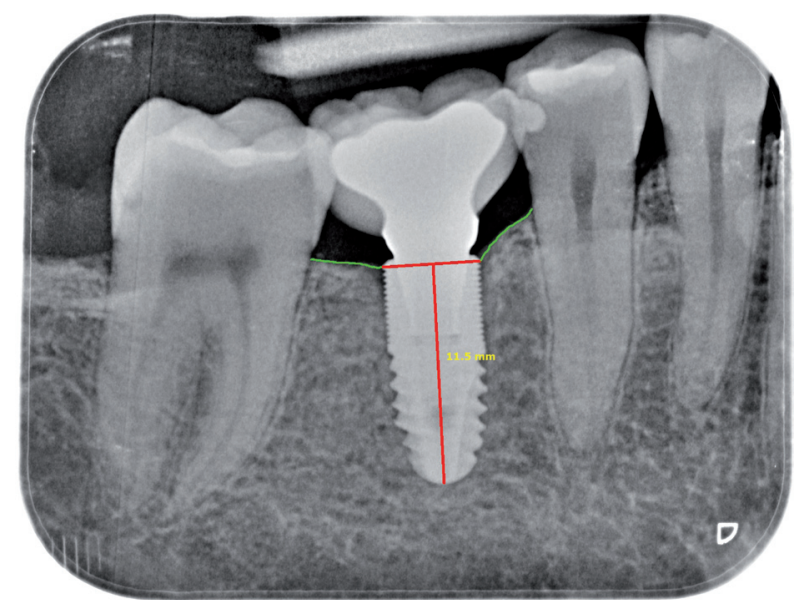

Fig. 1: Measurement of peri-implant bone loss with periapical X-ray view after 12 months of follow-up.

\section{-Statistical analysis}

A generalized estimating equation (GEE) linear model was used to evaluate differences in bone loss and in implant exposed surface, with measurement time as intraimplant factor and the group or type of edentulism as inter-implant factor. The main effects and interactions were studied using the Wald Chi2 statistic. Multiple comparisons were made with Bonferroni correction. For a generalized linear model with a significance level of $5 \%(p=0.05)$, and considering a mean detected effect size $(\mathrm{f}=0.25)$, the statistical power is 0.81 for null contrasting of the interaction.

\section{Results}

Thirty consecutive patients with the required type of edentulism were screened for the study. Five patients failed to meet the required criteria and were not included (two smoked >10 cigarettes/day; two required regeneration procedures; and one patient declined to participate). 
A flow diagram of the activities during the phases of the study is shown in Figure 2. Twenty-five patients (9 men and 16 women) between 27 and 80 years of age (mean 50.2 years) were considered eligible and were consecutively enrolled. Patient demographic and implant characteristics are listed in Table 2. No dropouts occurred during the entire follow-up period. Each patient could have one or more implants placed, according to the inclusion criteria. A total of 30 implants were placed: 15 allocated to each group. All patients completed follow-up and were analyzed. One implant failed during the osseointegration phase in group $\mathrm{A}$; the success rate was therefore $93.3 \%$ in group A and $100 \%$ in group B.

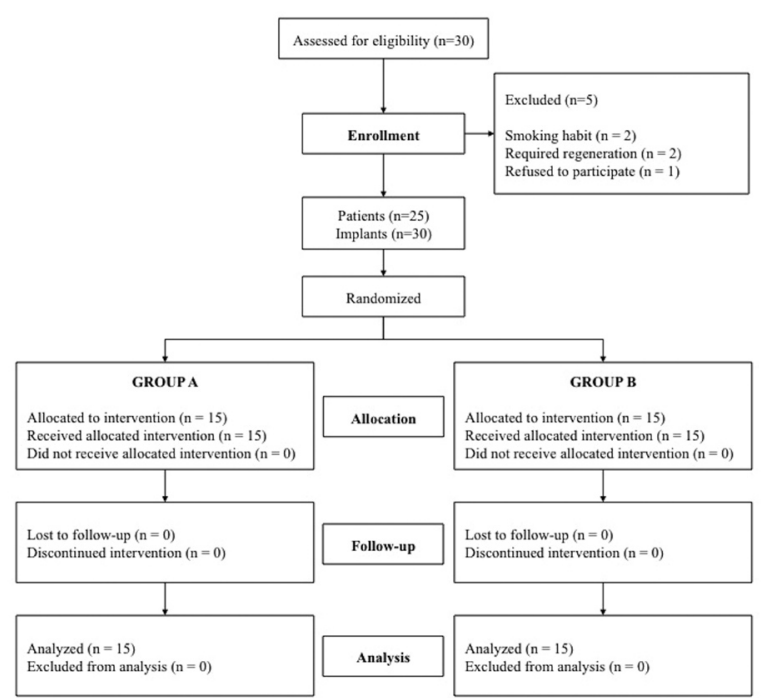

Fig. 2: Flow diagram of the study design.
Table 3 shows peri-implant bone level measurements of group A and group B implants at the different peri-implant points. At 12 months of follow-up, the mean bone loss of implants in group A and group B was $0.83 \pm 0.73$ $\mathrm{mm}$ and $0.70 \pm 0.62 \mathrm{~mm}$, respectively, with no significant difference between groups ( $p=0.458)$ (Fig. 3). With regard to implants placed in the maxilla, group $\mathrm{A}$ and group B showed a peri-implant bone loss of $0.59 \pm 0.80$ $\mathrm{mm}$ and $0.69 \pm 0,77 \mathrm{~mm}$ respectively, versus $1.04 \pm 0.63$ $\mathrm{mm}$ and $0.71 \pm 0.36 \mathrm{~mm}$ in the mandible.

\section{Discussion}

The aim of this study was to compare conventional

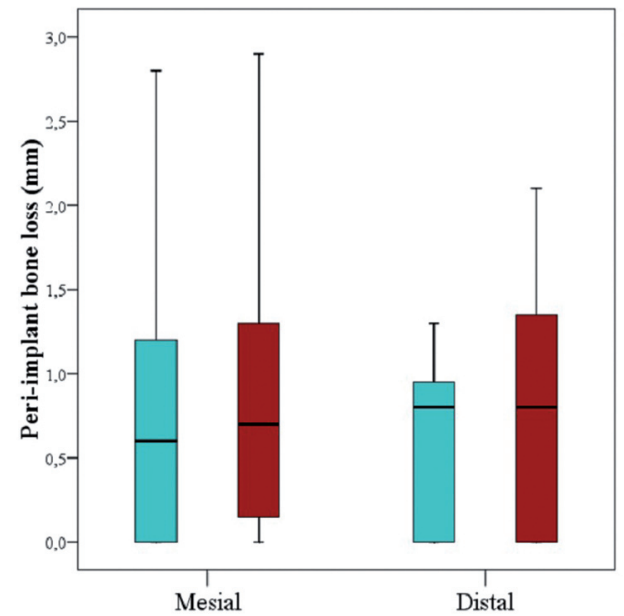

Group B

Group A

Fig. 3: Box plot of mesial and distal peri-implant bone loss in both groups.

Table 2: Patient demographic information and implant dimensions.

\begin{tabular}{|c|c|c|c|c|}
\hline & Total & Group A & Group B & $P$ value \\
\hline Age (mean) & \multicolumn{3}{|c|}{$49.3 \pm 13.5$ years (range $27-80$ years) } & $0.174(\mathrm{MW})$ \\
\hline Sex (n) & \multicolumn{3}{|c|}{9 males - 16 females } & 1.000 (FIS) \\
\hline Bone density (pixel) & \multicolumn{3}{|c|}{ Group A: $764.8 \pm 321.85$ - Group B: $728.2 \pm 291.7$} & $0.465(\mathrm{MW})$ \\
\hline \multicolumn{5}{|l|}{ Arch } \\
\hline Maxilla & 16 & 7 & 9 & \multirow[t]{2}{*}{0.464 (FIS) } \\
\hline Mandible & 14 & 8 & 6 & \\
\hline \multicolumn{5}{|l|}{ Posición } \\
\hline Premolar & 12 & 6 & 6 & \multirow[t]{2}{*}{0.611 (FIS) } \\
\hline Molar & 18 & 9 & 9 & \\
\hline \multicolumn{5}{|c|}{ Implant diameter (mm) (n) } \\
\hline 3.7 & 5 & 0 & 5 & \multirow[t]{3}{*}{$0.021(\mathrm{MW})$} \\
\hline 4.2 & 19 & 10 & 9 & \\
\hline 5.0 & 6 & 5 & 1 & \\
\hline \multicolumn{5}{|c|}{ Implant length $(\mathrm{mm})(\mathrm{n})$} \\
\hline 10 & 11 & 8 & 5 & \multirow[t]{3}{*}{$0.870(\mathrm{MW})$} \\
\hline 11.5 & 12 & 3 & 7 & \\
\hline 13 & 7 & 4 & 3 & \\
\hline
\end{tabular}


Table 3: Mesial, distal and mean measurements of peri-implant bone loss at 12 months of follow-up in groups A and B.

\begin{tabular}{|l|c|c|c|c|c|c|c|}
\hline \multirow{2}{*}{} & \multicolumn{3}{|c|}{ Group A } & \multicolumn{3}{c|}{ Group B } & $p$ value \\
& Total & Maxilla & Mandible & Total & Maxilla & Mandible & \\
\cline { 2 - 7 } & $0.89 \pm 0.85$ & $0.71 \pm 1.07$ & $1.04 \pm 0.64$ & $0.80 \pm 0.93$ & $0,87 \pm 1.18$ & $0.70 \pm 0.46$ & \\
\hline Distal & $0.77 \pm 0.71$ & $0.46 \pm 0.69$ & $1.05 \pm 0.64$ & $0.59 \pm 0.51$ & $0.51 \pm 0.58$ & $0.72 \pm 0.39$ & \\
\hline $\begin{array}{l}\text { Mean } \\
\text { bone loss }\end{array}$ & $0.83 \pm 0.73^{*}$ & $0.59 \pm 0.80^{\beta}$ & $1.04 \pm 0.63^{\beta}$ & $0.70 \pm 0.62^{*}$ & $0.69 \pm 0.77^{\beta}$ & $0.71 \pm 0.36^{\beta}$ & $0.458^{*}$ \\
\hline$p$ value (BL) & & & & & & & \\
\hline
\end{tabular}

BL: Brunner-Langer test.

drilling (at high speed with irrigation) versus low speed drilling without irrigation. One implant belonging to the irrigation group failed in our study - no relationship being observed between the technique applied and implant survival.

One of the main concerns of implant placement in drilling without irrigation is the temperature rise caused by drill friction in the bone. Using fixed thermal chambers, Eriksson and Albrektsson (7-21) investigated the histological effects of heat upon bone. When a temperature rise occurred, arterial and venous hyperemia was observed during acute effects, and blood flow stopped in different parts of the capillary network. There were no connective tissue reactions. A chronic effect was characterized by recirculation of the capillaries after four days, and was associated to slight elongation of the vessels. Adipose cells began to reabsorb two days after the thermal increase and continued to do so for 14 days. They changed in shape and color, and new fat cells were produced. At the third week about $30 \%$ of the bone had been resorbed. The authors concluded that in order to enable successful osseointegration of endosseous implants, low temperatures are required during preparation of the recipient site.

Different factors affect the heat generated during drilling at the implant site, including the operator (pressure, status, movement, speed and duration of drilling), manufacturer (design and sharpness of the drill, irrigation system and implant system), site (cortical thickness, condition of the site and depth drilled) and patient (age and bone density) (22). In an animal study, Trisi et al. (23) analyzed histomorphometric parameters in implants that had been placed with different irrigation systems (without irrigation, with internal irrigation, with external irrigation, and a combination of both). The results of the study suggest that due to insufficient irrigation, hard bone caused massive resorption of the cortical bone and implant failure. In all study groups, the drilling speed was $1000 \mathrm{rpm}$, justifying thermal injury in the group of non-irrigated implants. Sarendranath et al. (24), in a study in dogs, compared conventional drilling with a simplified drilling technique at $400 \mathrm{rpm}$ with irrigation. The results suggest that the simplified procedure yields biological outcomes comparable to those of the conventional procedure. Sung-Jong et al. (25) in turn evaluated the temperature change during low-speed drilling (50 rpm) using infrared thermography in pig ribs. The drilling technique did not produce heat exceeding $47^{\circ} \mathrm{C}$, which is the critical temperature for bone necrosis during low-speed drilling (7); thus, low-speed drilling without irrigation could be used during implant site preparation.

It seems evident that when a drilling protocol is used without irrigation, the drilling speed must be lowered to reduce friction, minimizing the temperature increase in the bone and thus avoiding thermal injury. In the present study, speeds of $800 \mathrm{rpm}$ were used in the group of implants placed with irrigation, versus $50 \mathrm{rpm}$ in the implants placed without irrigation. Most of the studies on bone overheating are made in vitro, mainly using two measurement methods: thermal chambers and thermocouples (26). These measurement systems cannot be applied in vivo, though other signs such as implant survival rate or peri-implant bone loss could be useful for analyzing the clinical impact of these drilling techniques in the implant bed of the patient. The principal outcome addressed in the present study were marginal bone loss 12 months after loading. Peri-implant marginal bone level was assessed using parallelized periapical radiographs. Mean bone loss after 12 months of follow-up was $0.83 \pm 0.73 \mathrm{~mm}$ in the irrigation group and $0.70 \pm 0.62$ $\mathrm{mm}$ in the non-irrigation group. No statistically significant differences were observed between irrigation and non-irrigation implant placement. No in vivo studies have evaluated the relationship between peri-implant bone loss and low-speed drilling. In group A, a peri-implant bone loss of $0.83 \pm 0.73 \mathrm{~mm}$ was observed, coinciding with the observations of a recent systematic review (27) of platform switching with conventional drilling, which demonstrated a range of marginal bone-level changes between $0.055-0.99 \mathrm{~mm}$. On the other hand, there are 
several studies corresponding to a brand of implants in which low-speed drilling without irrigation is specified in the surgical protocol, with an implant success rate of $97.3 \%$ after 5 years of follow-up (28). Al-Hashedi et al. (29) compared a type of implant placed with conventional drilling versus another implant placed with low-speed drilling without irrigation. The authors concluded that both implants demonstrated similar peri-implant soft tissue and alveolar bone changes.

In the present study, increased bone loss was observed in those implants placed in the mandible, regardless of the drilling technique used, and although these differences were not statistically significant given the limited sample size, the result suggests a very weak tendency $(p=0.165)$. These findings could be explained by the fact that thermal conductivity varies between cortical and cancellous bone, probably because of the different rate of vascular penetration (15). In a histological assessment of the effect of osteotomy in both types of bone, Stelzle et al. (4) recorded the highest temperature in the cortical areas.

Despite de reduced sample size (25 patients and 30 implants), the present study adds to the available evidence regarding the non-irrigation technique. The study comprised 25 consecutive patients selected on the basis of strict, uniform criteria and treated by the same team of professionals using exactly the same procedures. Within its limits, the present study suggests that the low-speed drilling technique without irrigation offers peri-implant bone loss outcomes similar to those of the conventional drilling technique. Further clinical studies with longer follow-up times and larger samples are needed to better understand the influence of the drilling technique (conventional speed with irrigation or low-speed without irrigation) upon peri-implant bone behavior, and to analyze the effects of the temperature rise.

\section{References}

1. Augustin G, Davila S, Mihoci K, Udiljak T, Vedrina DS, Antabak A. Thermal osteonecrosis and bone drilling parameters revisited. Archives of Orthopaedic and Trauma Surgery. 2008;128:71-7.

2. Misir AF, Sumer M, Yenisey M, Ergioglu E. Effect of surgical drill guide on heat generated from implant drilling. J Oral Maxillofac Surg. 2009;67:2663-8.

3. Scarano A, Piattelli A, Assenza B, Carinci F, Di Donato L, Romani GL. Infrared thermographic evaluation of temperature modifications induced during implant site preparation with cylindrical versus conical drills. Clin Implant Dent Relat Res. 2011;13:319-23.

4. Stelzle F, Frenkel C, Riemann M, Knipfer C, Stockmann P, Nkenke E. The effect of load on heat production, thermal effects and expenditure of time during implant site preparation - an experimental ex vivo comparison between piezosurgery and conventional drilling. Clin Oral Implants Res 2014;25:40-8.

5. Benington IC, Biagioni PA, Briggs J, Sheridan S, Lamey PJ. Thermal changes observed at implant sites during internal and external irrigation. Clin Oral Implants Res. 2002;13:293-7.

6. Marković A, Mišić T, Miličić B, Calvo-Guirado JL, Aleksić Z, Đinić A. Heat generation during implant placement in low-density bone: effect of surgical technique, insertion torque and implant macro design. Clin Oral Implants Res. 2013;24:798-805.

7. Eriksson AR, Albrektsson T. Temperature threshold levels for heat-induced bone tissue injury: a vital-microscopic study in the rabbit. The Journal of Prosthetic Dentistry. 1983;50:101-7.

8. Delgado-Ruiz RA, Sacks D, Palermo A, Calvo-Guirado JL, PerezAlbacete C, Romanos GE. Temperature and time variations during osteotomies performed with different piezosurgical devices: an in vitro study. Clin Oral Implants Res. 2016;27:1137-43.

9. Scarano A, Carinci F, Quaranta A, Di Iorio D, Assenza B, Piattelli A. Effects of bur wear during implant site preparation: an in vitro study. Int J Immunopathol Pharmacol. 2007;20:23-6.

10. Oliveira N, Alaejos-Algarra F, Mareque-Bueno J, Ferrés-Padró E, Hernández-Alfaro F. Thermal changes and drill wear in bovine bone during implant site preparation. A comparative in vitro study: twisted stainless steel and ceramic drills. Clin Oral Implants Res. 2012;23:963-9.

11. Strbac GD, Unger E, Donner R, Bijak M, Watzek G, Zechner W. Thermal effects of a combined irrigation method during implant site drilling. A standardized in vitro study using a bovine rib model. Clin Oral Implants Res. 2014;25:665-74.

12. Strbac GD, Giannis K, Unger E, Mittlböck M, Vasak C, Watzek G, et al. Drilling- and withdrawing-related thermal changes during implant site osteotomies. Clin Implant Dent Relat Res. 2015;17:32-43.

13. Strbac GD, Giannis K, Unger E, Mittlböck M, Watzek G, Zechner W. A novel standardized bone model for thermal evaluation of bone osteotomies with various irrigation methods. Clin Oral Implants Res. 2014;25:622-31.

14. Gehrke SA, Bettach R, Taschieri S, Boukhris G, Corbella S, Del Fabbro M. Temperature changes in cortical bone after implant site preparation using a single bur versus multiple drilling steps: an in vitro investigation. Clin Implant Dent Relat Res. 2015;17:700-7.

15. Oh HJ, Wikesjö UM, Kang HS, Ku Y, Eom TG, Koo KT. Effect of implant drill characteristics on heat generation in osteotomy sites: a pilot study. Clin Oral Implants Res. 2011;22:722-6.

16. Jeong SM, Yoo JH, Fang Y, Choi BH, Son JS, Oh JH. The effect of guided flapless implant procedure on heat generation from implant drilling. J Craniomaxillofac Surg. 2014;42:725-9.

17. A Turkyilmaz I, Tumer C, Ozbek EN, Tözüm TF. Relations between the bone density values from computerized tomography, and implant stability parameters: a clinical study of 230 regular platform implants. J Clin Periodontol 2007; 34:716-22.

18. Song YD, Jun SH, Kwon JJ. Correlation between bone quality evaluated by cone-beam computerized tomography and implant primary stability. Int J Oral Maxillofac Implants 2009;24:59-64.

19. Deeb GR, Soung GY, Best AM, Laskin DM. Antibiotic Prescribing Habits of Oral and Maxillofacial Surgeons in Conjunction With Routine Dental Implant Placement. J Oral Maxillofac Surg. 2015;73:1926-31.

20. Buser D, Janner SF, Wittneben JG, Brägger U, Ramseier CA, Salvi GE. 10-year survival and success rates of 511 titanium implants with a sandblasted and acid-etched surface: a retrospective study in 303 partially edentulous patients. Clin Implant Dent Relat Res. 2012;14:839-851.

21. Eriksson RA, Adell R. Temperatures during drilling for the placement of implant using the osseointegration technique. J Oral Maxillofac Surg. 1986;44:4-7.

22. Tehemar S. H. Factors affecting heat generation during implant site preparation: a review of biologic observations and future considerations. Int J Oral Maxillofac Implants. 1999;14:127-36.

23. Trisi P, Berardini M, Falco A, Vulpiani MP, Masciotra L. Effect of 50 to $60^{\circ} \mathrm{C}$ heating on osseointegration of dental implants in dense bone: an in vivo histological study. Implant Dent. 2014;23:516-21.

24. Sarendranath A, Khan R, Tovar N, Marin C, You D, Redisch J, et al. Effect of low speed drilling on osseointegration using simplified drilling procedures. Br J Oral Maxillofac Surg. 2015;53:550-6.

25. Kim SJ, Yoo J, Kim YS, Shin SW. Temperature change in pig rib bone during implant site preparation by low-speed drilling. J Appl Oral Sci. 2010;18:522-7.

26. Möhlhenrich SC, Modabber A, Steiner T, Mitchell DA, Hölzle F. Heat generation and drill wear during dental implant site preparation: systematic review. Br J Oral Maxillofac Surg. 2015;53:679-89. 
27. Herekar M, Sethi M, Mulani S, Fernandes A, Kulkarni H. Influence of platform switching on periimplant bone loss: a systematic review and meta-analysis. Implant Dent. 2014;23:439-50.

28. Demiralp KÖ, Akbulut N, Kursun S, Argun D, Bagis N, Orhan K. Survival rate of short, locking taper implants with a plateau design: a 5-year retrospective study. Biomed Res Int. 2015;2015:197451.

29. Al-Hashedi AA, Taiyeb-Ali TB, Yunus N. Outcomes of placing short implants in the posterior mandible: a preliminary randomized controlled trial. Aust Dent J. 2016;61:208-18.

\section{Acknowledgments}

The authors greatly appreciate the skills and dedication of Juan Luis Gómez Martínez in the provided statistical support.

\section{Conflict of Interests}

All the authors declare that they have no competing interests. 